\title{
Interactions between the Glycine and Glutamate Binding Sites of the NMDA Receptor
}

\author{
Robin A. J. Lester, ${ }^{a}$ Gang Tong, and Craig E. Jahr \\ Vollum Institute and the Department of Cell Biology and Anatomy, Oregon Health Sciences University, Portland, Oregon \\ 97201-3098
}

The interactions between the glycine and glutamate binding sites of the NMDA receptor have been studied in outsideout patches and synapses from hippocampal neurons in culture using rapid drug application techniques. Desensitization of NMDA receptor-mediated currents elicited by glutamate in newly excised outside-out patches was reduced in the presence of saturating concentrations of glycine. This suggests that the glutamate and glycine binding sites of the NMDA receptor are allosterically coupled as has been reported in whole-cell preparations. A glycine-insensitive form of desensitization increased rapidly over the first few minutes of recording and largely occluded the glycine concentration-sensitive desensitization in outside-out patches. However, even in old patches that displayed no glycinesensitive desensitization, the unbinding rate of glycine was increased fourfold by the presence of glutamate, suggesting that the two binding sites were still allosterically coupled. These data suggest the existence of two forms of NMDA receptor desensitization in outside-out patches, only one of which is dependent on the concentration of glycine. In the presence of saturating levels of glycine, activation of NMDA receptors by synaptic stimulation or by exogenous glutamate resulted in currents that relaxed biexponentially. Addition of the partial glycine-site agonist 1-hydroxy-3-aminopyrrolid-2-one (HA-966) increased the rate of decay of both synaptic and patch currents. This suggests that HA966 increases the dissociation rate of glutamate from NMDA receptors. These results support the hypothesis that the glutamate and glycine binding sites of NMDA receptors interact allosterically; ligand binding at both types of sites can affect the affinity of the other type for its agonist.

[Key words: NMDA receptor channel, synaptic transmission, desensitization, glutamate, glycine, outside-out patch]

Both the neurotransmitter L-glutamate (glutamate) and the coagonist glycine are necessary to permit channel opening and synaptic activation of NMDA receptors (Johnson and Ascher, 1987; Forsythe et al., 1988; Kleckner and Dingledine, 1988). However, the precise mode of interaction of glycine with the NMDA re-

\footnotetext{
Received June 22, 1992; revised Sept. 8, 1992; accepted Sept. 17, 1992.

We thank Mr. J. Volk for making and maintaining the cell cultures. This work was supported by NIH Grant NS21419.

Correspondence should be addressed to Craig E. Jahr, Vollum Institute L-474, Oregon I lealth Sciences University, 3181 SW Sam Jackson Park Road, Portland, OR 97201-3098.

aPresent address: Department of Molecular Physiology and Biophysics, Baylor College of Medicine, One Baylor Plaza, Houston, TX 77030.

Copyright (C) 1993 Society for Neuroscience $0270-6474 / 93 / 131088-09 \$ 05.00 / 0$
}

ceptor is controversial (see Thomson, 1991). In whole-cell recordings from hippocampal neurons, saturating concentrations of glycine prevent, for the most part, desensitization of NMDA receptor-mediated currents (Mayer et al., 1989). They proposed that the binding of an agonist at the NMDA binding site causes an allosteric reduction in the affinity of the receptor for glycine. As glycine is required for channel opening, at low concentrations of glycine the NMDA receptor current declines with a time course that reflects reequilibration of glycine with its binding site. Raising the level of glycine reduces this form of desensitization by overcoming the decrease in affinity (Benveniste et al., 1990; Vyklicky et al., 1990). However, in outside-out patches and some whole-cell recordings, desensitization proceeds at a similar rate irrespective of the concentration of glycine, suggesting that NMDA receptor behavior varies across preparations (Sather et al., 1990). Because the glycine-insensitive form of desensitization increases with the duration of recording, possibly through the loss of cytoplasmic factors, the interpretation of allosteric interactions in outside-out patches and small cells is complicated (Benveniste et al., 1990; Chizhmakov et al., 1992; Lester and Jahr, 1992; Sather et al., 1992).

The present study provides evidence that allosteric interactions occur between the glutamate and glycine binding sites of the NMDA receptor in outside-out patches and can result in a glycine concentration-dependent form of desensitization. However, due to a time-dependent increase in the rate into a glycineinsensitive desensitized state, glycine concentration-dependent desensitization is observed only transiently in outside-out patches. Because most studies have not compared synaptic and extrasynaptic receptors, we have also examined the effect of glycine concentration on the kinetics of synaptically activated NMDA currents. The data suggest that the kinetic behavior of NMDA receptors is remarkably similar across many types of preparations and recording conditions.

\section{Materials and Methods}

Cell culture. Experiments were performed on hippocampal neurons prepared from 1-3-d-old neonatal rats and maintained in primary cell culture for 1-3 weeks, as described previously (Lester et al., 1989).

Outside-out patch recordings. Outside-out patch recordings (Axopatch-1C, Axon Instruments, Foster City, CA) from hippocampal neurons were obtained using pipettes containing Na-gluconate or Na-methanesulfonate, $140 \mathrm{~mm}$; $\mathrm{NaCl}, 10 \mathrm{~mm}$; HEPES, $10 \mathrm{~mm}$; EGTA, $10 \mathrm{~mm}$; $\mathrm{Mg}-\mathrm{ATP}, 4 \mathrm{~mm}$; and GTP, $100 \mu \mathrm{M}$; adjusted to pH 7.4 with $\mathrm{NaOH}$. Control external solutions contained $\mathrm{NaCl}, 160 \mathrm{mM} ; \mathrm{KCl}, 3 \mathrm{mM}$; HEPES, $5 \mathrm{~mm}$; glycine, $0.01 \mathrm{~mm}$; and 6-cyano-7-nitroquinoxaline-2,3-dione (CNQX), $0.002 \mathrm{~mm}$; adjusted to $\mathrm{pH} 7.4$ with $\mathrm{NaOH}$. $\mathrm{Ca}^{2+}$ was usually present at $0.2 \mathrm{~mm}$, although in some experiments none was added to an external solution that contained $1 \mathrm{~mm}$ EGTA. External solutions were gravity fed into the lumens of either four-barreled $(2 \times 2)$ or three- 
barreled square-glass tubing (Vitro Dynamics, Inc., Rockaway, NJ) with each lumen pulled to a size of about $50 \mu \mathrm{m}$ across. The barrels were attached to a piezoelectric bimorph (Vernitron, Bedford, $\mathrm{OH}$ ). The patch was positioned within $50 \mu \mathrm{m}$ of the barrels, near the interface formed between the continuously flowing solutions. By applying a voltage (isolated stimulator, Winston Electronics, Millbrae, CA) across the bimorph and thereby moving the solution interface across the tip of the patch pipette, solution exchanges were effected. Multiple solution exchanges could be achieved by stepping across a series of solutions using additional stimulators arranged in series. Agonist applications were made at 10-30 sec intervals. Outside-out patches were clamped at $-60 \mathrm{mV}$, and the currents were low-pass filtered at $0.1-1.0 \mathrm{kHz}$ and digitally sampled at 500-2000 IIz. High-purity salts were obtained from Aldrich (gold label). Other chemicals were obtained from Sigma, except for CNQX and 7-chlorokynurenic acid (7-Cl-kyn) (Cambridge Research Biochemicals and Tocris). In experiments in which patches were preincubated in glutamate alone, channel activity was greatly attenuated by using HPLC grade water (Mallinckrodt, Paris, KY) for all solutions and by using HPLC grade glutamate and glycine standards (Sigma). The speed and completeness of solution changes were routinely tested at the end of a recording by "blowing out" the membrane and monitoring the open tip current due to differences in liquid junction potentials in the control and drug solutions (the agonist solutions were diluted by the addition of 1 part water to 50 parts solution). Illustrated traces are averages of 4-32 responses.

Synaptic experiments. Whole-cell patch-clamp (Warner Instruments, Hamden, CT) recordings from two cells were obtained using 3-5 M $\Omega$ pipettes filled with an internal solution containing K-gluconate, 150 $\mathrm{mM}$; $\mathrm{NaCl}, 10 \mathrm{mM}$; HEPES, $10 \mathrm{~mm}$; and EGTA, $10 \mathrm{~mm}$; adjusted to pH 7.4 with $\mathrm{KOH}$. The control external solution contained $\mathrm{NaCl}, 160$ $\mathrm{mm}$; $\mathrm{KCl}, 3 \mathrm{~mm} ; \mathrm{CaCl}_{2}, 2 \mathrm{~mm}$; HEPES, $10 \mathrm{~mm}$; glycine $0.02 \mathrm{~mm}$; picrotoxin, $0.05 \mathrm{~mm}$; and CNQX, $0.005 \mathrm{~mm}$; adjusted to $\mathrm{pH} 7.4$ with $\mathrm{NaOH}$. Both pre- and postsynaptic neurons were voltage clamped. A brief (1-2 msec) depolarizing voltage step from a holding potential of $-60 \mathrm{mV}$ evoked an action potential in the presynaptic cell, and the postsynaptic current was clamped at potentials in the range of -60 to $-90 \mathrm{mV}$. In some cases autaptic synapses were studied (Bekkers and Stevens, 1991). Synaptic currents were croked at 8-20 scc intervals, low-pass filtered at $1 \mathrm{kHz}$, and digitally sampled at $2 \mathrm{kHz}$. Synapses were continuously superfused with external solution flowing through an array of glass barrels (internal diameter, $400 \mu \mathrm{m}$; Garner Glass, Clairmont, CA). Rapid solution exchange at synapses was effected by simultaneously turning off one barrel and turning on an adjacent barrel. The time constant for the exchange has been estimated previously as $30-40 \mathrm{msec}$ (Lester et al., 1990). Illustrated traces are averages of two to eight responses.

All experiments were performed at room temperature $\left(25^{\circ} \mathrm{C}\right)$.

Data analysis. Unless otherwise indicated, all data are expressed as the mean \pm SEM. Single and double exponentials were fitted to the current relaxations using a least-squares fitting routine (AxoGraph, Axon Instruments). Averaged outside-out patch responses were fitted with the multi-state kinetic model describcd in the Rcsults using a least-squares fitting procedure (scop program, Simulation Resources, Berrien Springs, $\mathrm{MI}$ ).

\section{Results}

NMDA receptor desensitization is dependent on the concentration of glycine

As shown previously (Sather et al., 1990; Lester and Jahr, 1992), rapid applications of glutamate to outside-out patches in the presence of glycine produce currents that decay rapidly during the continuous application of agonist. Because the extent of desensitization varies from patch to patch and its rate increases with time (Chizhmakov et al., 1992; Lester and Jahr, 1992; Sather et al., 1992), examination of the glycine sensitivity of desensitization requires that the different drug solutions be alternately applied to the same patch (see Lester and Jahr, 1992). Figure $1 A$ shows "early" (within the first $2 \mathrm{~min}$ ) and "late" (3$5 \mathrm{~min})$ responses to $400 \mathrm{msec}$ applications of glutamate (200 $\mu \mathrm{M})$ in the presence of low $(100 \mathrm{nM})$ and high $(20 \mu \mathrm{M})$ background concentrations of glycine. In both cases the response amplitude

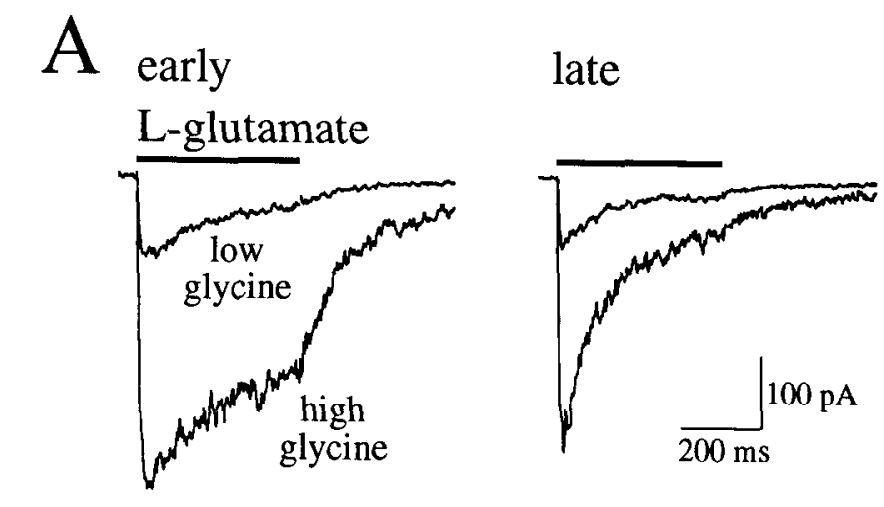

\section{B}

\section{normalized}

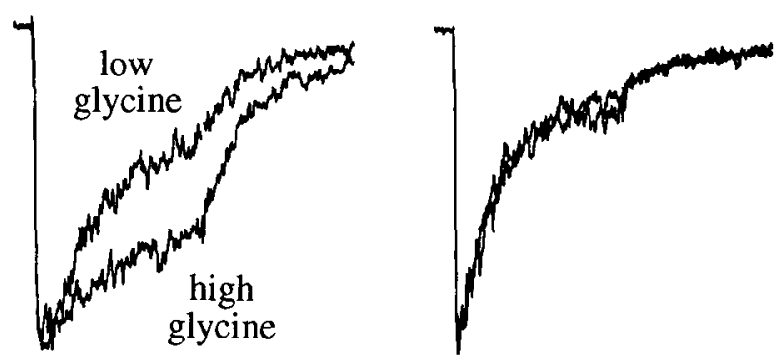

Figure 1. Time-dependent changes in the rate of desensitization mask the glycine-sensitive modulation of NMDA receptors. $A$, Averaged currents in response to a $400 \mathrm{msec}$ application of glutamate $(200 \mu \mathrm{M})$ in $100 \mathrm{nM}$ and $20 \mu \mathrm{M}$ background glycine within $2 \mathrm{~min}(l e f t)$ and 3-5 min (right) of obtaining the outside-out patch. $B$, The traces in $A$ normalized to the peak of the responses in low and high glycine for both the early and late time points. All responses are from the same patch.

is smaller in low glycine, in agreement with the potentiating effect of glycine (Johnson and Ascher, 1987). However, if the responses are normalized to their peak currents, a clear difference in their behavior in high and low glycine is observed at the two time points (Fig. $1 B$ ). Only at early times is desensitization sensitive to the glycine concentration. The model suggested by Benveniste et al. (1990) to account for the glycine sensitivity of NMDA receptor desensitization predicts that when an agonist of the NMDA site binds, there is a reduction in the affinity of the receptor for glycine. The time-dependent decline in glycine sensitivity illustrated in Figure 1 could therefore be due to an uncoupling of the NMDA and glycine sites or a timedependent increase in a second, glycine-insensitive form of desensitization that masks the glycine-sensitive form.

\section{Glutamate increases the rate of dissociation of glycine from NMDA receptors}

If the allosteric interaction between the NMDA and glycine binding sites is still present in "late" patches but is masked by the emergence of another form of desensitization, then the affinity of glycine should be decreased by glutamate even in "late" patches. This can be tested by measuring the unbinding rate of glycine in the presence and absence of glutamate, assuming that its affinity depends at least in part on its rate of dissociation. A method to estimate the unbinding of glycine in the absence of glutamate is shown in Figure 2. Outside-out patches were bathed in a saturating concentration of glycine $(20 \mu \mathrm{M})$. At the time indicated by the arrowhead, a glycine-free medium was introduced, and brief $(10 \mathrm{msec})$ pulses of glutamate $(200 \mu \mathrm{M})$ were applied at various intervals following this exchange. The am- 

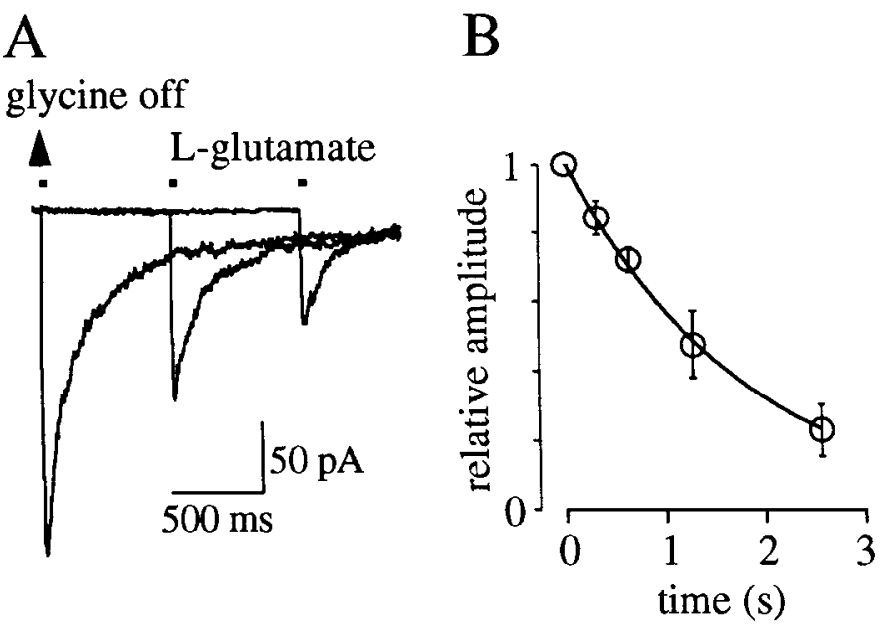

Figure 2. Measurement of the dissociation rate of glycine from the NMDA receptor in the absence of glutamate. $A$, Averaged NMDA receptor currents in response to $10 \mathrm{msec}$ pulses of glutamate $(200 \mu \mathrm{M})$ applied at various times (squares) following the removal of glycine (20 $\mu \mathrm{M})$ from an outside-out patch (arrowhead). B, Plot of the mean normalized amplitudes of the currents with respect to the time of application ( $n=4$ for the first two time points and $n=3$ for the last two time points). The continuous line is the exponential decay predicted by the model (see Fig. 3) and has a time constant of $1774 \mathrm{msec}$.

plitude of the responses to glutamate decreased with time after introduction of glycine-free medium (Fig. $2 A$ ). If the relative amplitude of these currents reflects the occupancy of the glycine site, a plot of amplitude against time should represent the time course of glycine unbinding (Fig. $2 B$ ). This time course was well fitted by a single exponential with a time constant of $1760 \mathrm{msec}$ and suggests an apparent dissociation rate constant of $0.57 \mathrm{sec}^{-1}$. Since there are probably two identical and independent binding sites for glycine (Benveniste and Mayer, 1991; Clements and Westbrook, 1991; but see Johnson and Ascher, 1992), the microscopic unbinding rate for glycine will be twice as slow, 0.28 $\sec ^{-1}$.

The unbinding rate of glycine in the presence of glutamate may be estimated from the decay of the current following a short pulse of glycine in a continuous background of glutamate (Benveniste et al., 1990). However, the unbinding rate of glycine cannot be directly extracted from the relaxation of the current in outside-out patches because it is the result of both unbinding and desensitization, similar to that of currents evoked by short pulses of glutamate in continuous glycine (Lester and Jahr, 1992). The decay is well fitted with a double exponential function (Fig. $3 A$ ) with mean time constants of $225 \pm 31 \mathrm{msec}$ and $2354 \pm$ $759 \mathrm{msec}(n=7)$. Without the ability to prevent the glycine concentration-independent desensitization, it is not possible to obtain an unbinding rate for glycine directly from these time constants. However, using a multistate model for the NMDA receptor, the rate of dissociation of glycine in the presence of glutamate can be estimated. The model is similar to that described by Benveniste et al. (1990) and consists of two independent, but equivalent, binding sites for both glutamate $\left(\mathrm{R}_{\mathrm{GLU}}\right)$ and glycine $\left(\mathrm{R}_{\mathrm{GLY}}\right)$ (for simplicity, only one site for each agonist is shown in the state diagram). Additional open (conducting, $\mathrm{O}$ ) and desensitized ( $D_{G \text { GuGLY }}$ ) states that can only be accessed from the doubly bound glutamate/glycine state $\left(R_{\text {GLUGLY }}\right)$ are included.
A

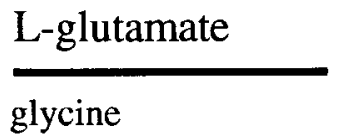

B
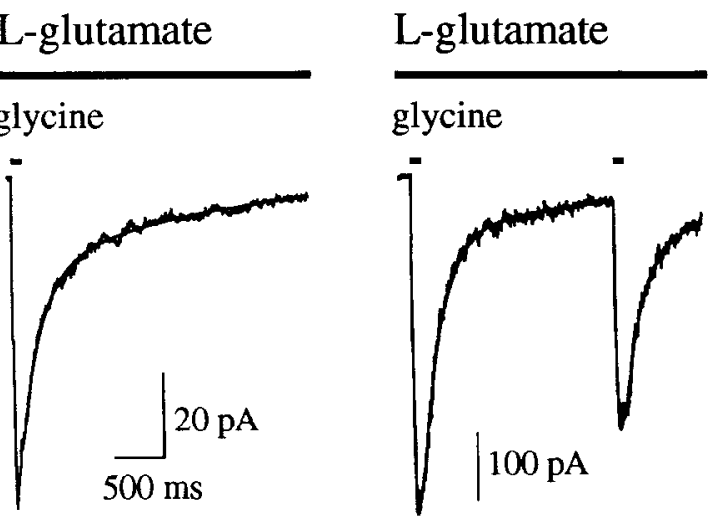

glycine

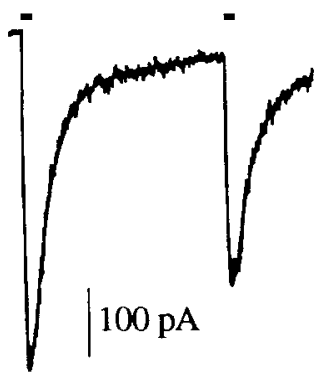

Figure 3. Estimation of the dissociation rate of glycine from the NMDA receptor in the presence of glutamate. $A$, Averaged NMDA currents in response to a $100 \mathrm{msec}$ application of glycine $(200 \mu \mathrm{M})$ to an outsideout patch in the continuous presence of glutamate $(200 \mu \mathrm{M})$. The decay is described by a double exponential (smooth line). $B$, Paired-pulse application of glycine to a different patch in the presence of glutamate. The rate of unbinding of glycine was estimated by fitting the model (smooth line) to the responses.

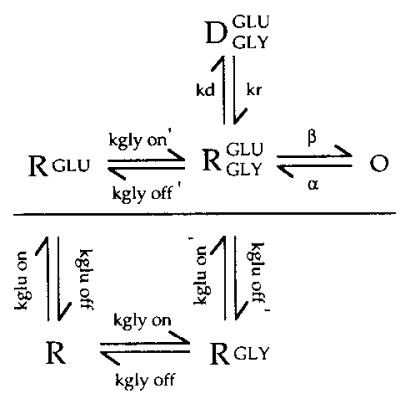

When glutamate is continuously present in saturating concentrations, the model simplifies to that shown above the solid line. In order to generate responses to be fitted by the model, $100 \mathrm{msec}$ paired pulses of glycine $(200 \mu \mathrm{M} ; 2 \mathrm{sec}$ interpulse interval) were applied in the presence of background glutamate $(200 \mu \mathrm{M})$. Paired pulses were used because the peak of the second response is extremely sensitive to the rates into and out of desensitized state, thereby setting much more stringent requirements for the fitting process. The peak open probability was set to 0.3 (Jahr, 1992). As the concentration of glycine was very high, its binding was nearly instantaneous and therefore its binding rate was not determined but rather was constrained to 5.9 $\mu \mathbf{M}^{-1} \sec ^{-1}$ (Benveniste et al., 1990). The other five rate constants were allowed to vary. The mean microscopic unbinding rate for glycine in the presence of glutamate $\left(k_{\text {gly off }}\right)$ was estimated to be $1.3 \pm 0.3 \sec ^{-1}(n=5)$. The rates for channel opening $(\beta)$, closing $(\alpha)$, desensitization $\left(k_{d}\right)$, and resensitization $\left(k_{r}\right)$ are shown in Table 1 and are similar to those previously obtained (Clements and Westbrook, 1991; Lester and Jahr, 1992). Furthermore, the apparent unbinding rates for glycine in the presence $\left(k_{\mathrm{gly} \text { off }}\right)$ and absence $\left(k_{\mathrm{gly} \text { off }}\right)$ of glutamate are very similar to those measured by Benveniste et al. (1990) for wholecell NMDA responses. The greater than fourfold increase in the apparent rate of dissociation of glycine in the presence of glutamate is consistent with a reduction in its affinity. Therefore, we suggest that the inability to observe glycine-sensitive desensitization in outside-out patches at "late" stages is not caused 


\section{Table 1. Model rate constants}

$\begin{array}{llc}\text { Opening } & \beta & 104 \mathrm{sec}^{-1 a} \\ \text { Closing } & \alpha & 285 \mathrm{sec}^{-1 a} \\ \text { Desensitization } & k_{d} & 5.1 \mathrm{sec}^{-1} a \\ \text { Resensitization } & k_{r} & 0.95 \mathrm{sec}^{-1} a \\ k_{\text {glycine on }} & k_{\mathrm{gly} \text { on }} & 11 \mu \mathrm{M}^{-1} \mathrm{sec}^{-1 b} \\ k_{\text {glycine off }} & k_{\mathrm{gly} \text { off }} & 0.28 \mathrm{sec}^{-1 a} \\ k_{\text {glutamate on }} & k_{\mathrm{glu} \text { on }} & - \\ k_{\text {glutamate off }} & k_{\text {glu off }} & 5 \mathrm{sec}^{-1} \\ k_{\text {glycine on (glutamate bound) }} & k_{\text {gly on' }} & 5.9 \mu \mathrm{M}^{-1} \mathrm{sec}^{-1 b} \\ k_{\text {glyrine off (glutamate hound) }} & k_{\text {gly off }} & 1.3 \mathrm{sec}^{-1} a \\ k_{\text {glutamatc on (glycine bound) }} & k_{\text {glu on' }} & 5 \mu \mathrm{M}^{-1} \mathrm{sec}^{-1} d \\ k_{\text {glutamate off (glycine bound) }} & k_{\text {glu off }} & 5 \mathrm{sec}^{-1} d\end{array}$

a Obtained in the present study.

" From Benveniste et al. (1990).

c Free to permit microscopic reversibility.

${ }^{d}$ From Clements and Westbrook (1991).

by an uncoupling of the two binding sites, but rather by the progressive increase of a second form of glycine-insensitive desensitization that masks the effects of a change in the affinity of glycine.

\section{Synaptic NMDA receptors are allosterically regulated at the glycine site}

Although it is known that glycine is required for activating NMDA EPSCs (Forsythe et al., 1988; Thomson et al., 1989), it is unclear whether the allosteric interactions observed in outside-out patch and whole-cell recordings occur at the glycine site of synaptic NMDA receptors. The obvious tcst is to examine the effects of glycine concentration on the decay of the EPSC. Although low glycine significantly decreased the peak amplitude of the EPSC (Fig. $4 A$ ), the decay phase was largely unaltered, as shown in the normalized responses (Fig. $4 B$ ). Lowering the concentration of glycine from $20 \mu \mathrm{M}$ to $100 \mathrm{nM}$ had no effect on the time constant of the fast relaxation component of the NMDA EPSC $(78.9 \pm 4.7 \mathrm{msec}$ in low glycine vs $79.0 \pm 6.6$ msec in high glycine; $n=9$ ). This result suggests that glycinesensitive desensitization does not play an important role at synaptic NMDA receptors. However, even in the presence of glutamate, the dissociation rate of glycine is slow relative to the decay time course of the NMDA EPSC (Fig. 5). Switching out of glycine and into a glycine site antagonist [7-Cl-kyn, $30 \mu \mathrm{M}$ or

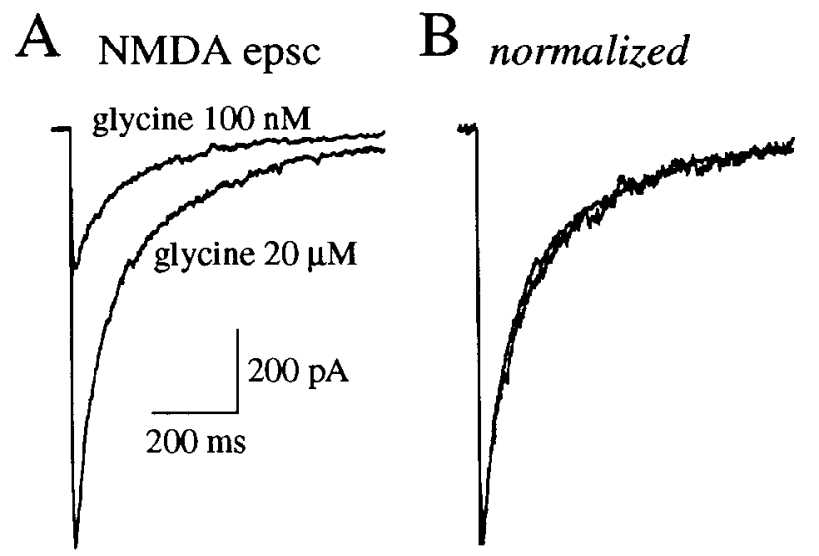

Figure 4. The kinetics of the NMDA EPSC are insensitive to the concentration of glycine. $A$, Averages of the NMDA EPSC in the presence of $100 \mathrm{nM}$ and $20 \mu \mathrm{M}$ glycine from the same synapse. $B$, The traces in $A$ are normalized to show the similarity in the EPSC decay.

\section{A NMDA epsc}

\section{outside-out patch}
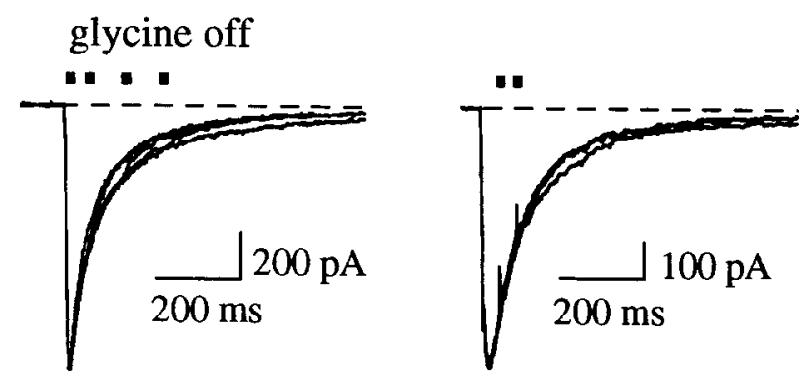

$\mathrm{B}$

L-alanine off
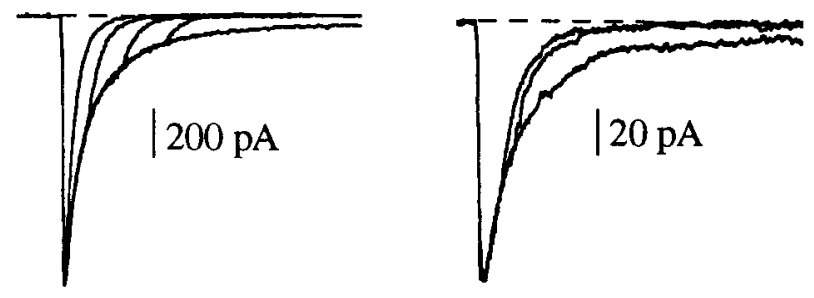

Figure 5. Glycine dissociates slowly from synaptic and patch NMDA receptors. $A$, Superimposed, averaged currents in response to synaptic stimulation (left) and a $10 \mathrm{msec}$ application of $200 \mu \mathrm{M}$ glutamate to an outside-out patch (right), in the continuous presence of saturating levels glycine and during removal of glycine (and addition of the glycine antagonist $7-\mathrm{Cl}-\mathrm{kyn}, 30 \mu \mathrm{M}$ ) at the times indicated by the squares. $B$, The same paradigm as in $A$ except that L-alanine ( $500 \mu \mathrm{M})$ was substituted for glycine. The EPSCs are from the same synapse. Different patches were used in $A$ and $B$.

5-fluoroindole carboxylic acid, (FIC), 2 mM; see Huettner, 1991] slightly increased the decay rates of both EPSCs and patch responses to $10 \mathrm{msec}$ glutamate applications (Fig. $5 \mathrm{~A}$ ), consistent with the slow unbinding of glycine. If, however, the lower-affinity glycine site agonist L-alanine $(500 \mu \mathrm{M})$ was used, its removal resulted in very fast decays of both currents, indicating that the dissociation rate of $\mathrm{L}$-alanine is much faster than that of glycine and that glycine site ligands can dissociate during NMDA receptor activation (Fig. $5 B$ ). Furthermore, not only is a glycine site agonist required for receptor activation, but its continued binding is necessary for channel opening. However, these experiments still leave the question of allosteric interaction at synaptic NMDA receptors unresolved.

Recently, Kemp and Priestley (1991) reported that the glycine-site partial agonist 3-amino-1-hydropyrrolid-2-one (HA966; Fletcher and Lodge, 1988; Henderson et al., 1990) reduced the affinity of glutamate for the NMDA receptor, largely by increasing its rate of dissociation. From the behavior of loweraffinity NMDA ligands (Lester and Jahr, 1992), we can predict that HA-966 should cause a faster decay of the NMDA EPSC. In the presence of $300 \mu \mathrm{M}$ HA-966 and $300 \mathrm{~nm}$ glycine, activation of NMDA receptors either synaptically or by a brief application of glutamate $(200 \mu \mathrm{M}, 10 \mathrm{msec})$ evoked currents that were both smaller and decayed faster than in glycine alone (Fig. 6 ). A double exponential fit to the decay revealed that the time constant of the fast decay component decreased from $88 \pm 5$ msec in $300 \mathrm{~nm}$ glycine alone to $40 \pm 2 \mathrm{msec}$ in HA-966 for the patch $(n=8)$ and from $78.9 \pm 4.7 \mathrm{msec}$ to $41.7 \pm 2.0 \mathrm{msec}$ for the synapse $(n=6)$. The second, slower component contributed only $9 \%$ and $26 \%$ in HA-966 compared to $31 \%$ and 

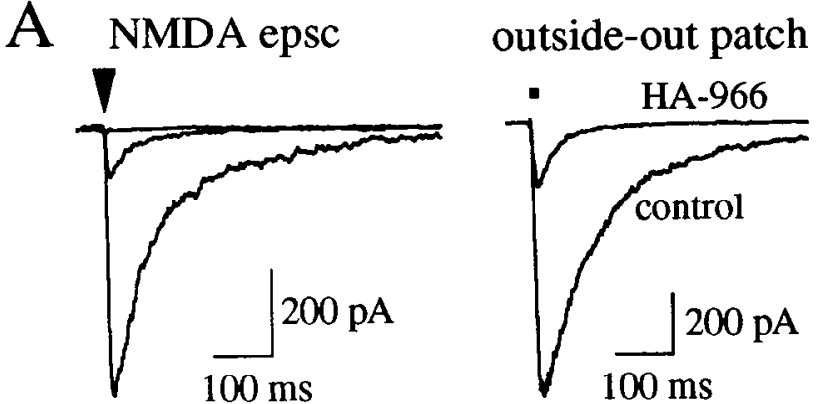

B
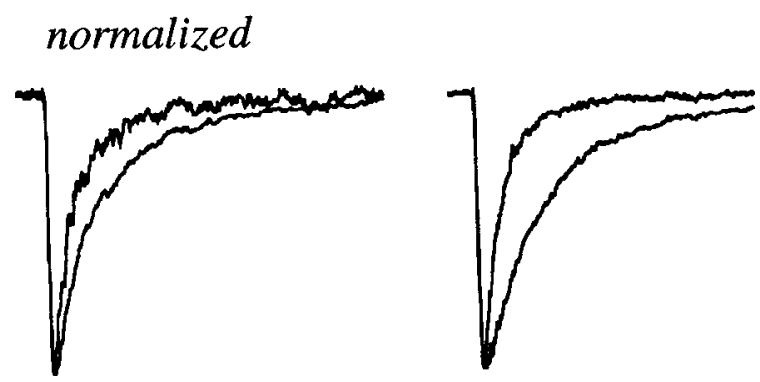

Figure 6. NMDA currents decay faster in the presence of HA-966. A, NMDA currents activated either synaptically in dual whole-cell recordings (left) or by glutamate $(10 \mathrm{msec} ; 200 \mu \mathrm{M})$ in an outside-out patch (right), in continuous glycine ( $300 \mathrm{nM}$ ) with or without HA-966 (300 $\mu \mathrm{M})$ added. The flat trace $(A$, left $)$ shows total block of the response in D-APV $(50 \mu \mathrm{M}) . B$, The traces in $A$ normalized to peak.

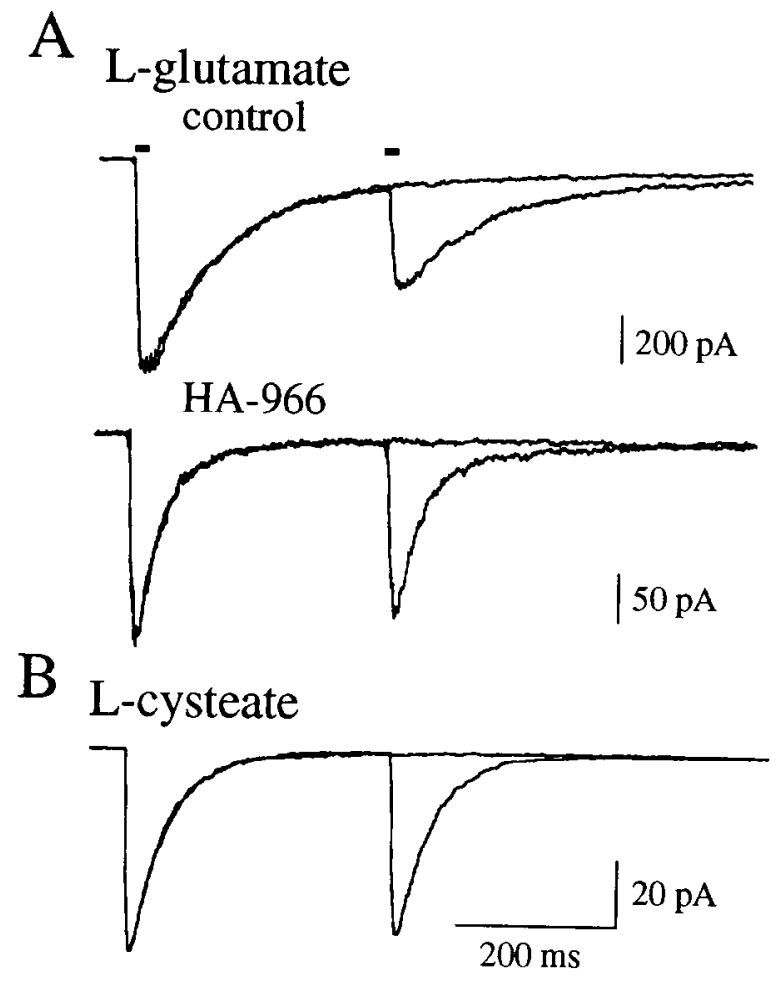

Figure 7. Glutamate acts as a lower-affinity NMDA ligand in the presence of HA-966. $A$, Paired-pulse responses to glutamate $(10 \mathrm{msec}, 200$ $\mu \mathrm{M}$ ) in background glycine ( $300 \mathrm{nM}$ ) alone (upper trace) or with added HA-966 (300 $\mu \mathrm{M}$; lower trace). $B$, From a different patch, paired-pulse responses to $\mathrm{L}$-cysteate $(20 \mathrm{mM})$ in continuous glycine $(10 \mu \mathrm{M})$.
A

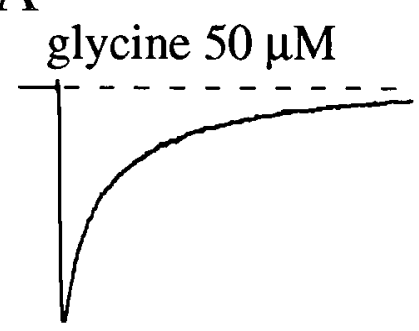

B

$\mathrm{C}$
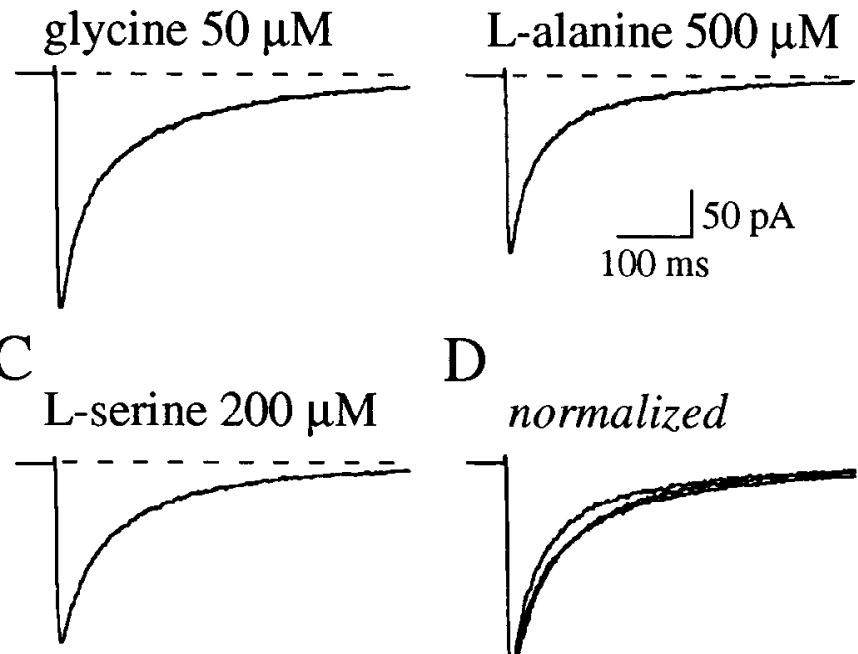

$\mathrm{D}$

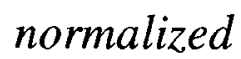

Figure 8. Comparison of different glycine site agonists on the decay of the NMDA EPSC: averaged NMDA EPSCs evoked in the continuous presence of glycine $(A)$, L-alanine $(B)$, and L-serine $(C)$. $D$, The traces are normalized and superimposed to show the faster decay of the EPSC evoked in L-alanine. All responses are from the same synapse.

$35 \%$ in control, for the patch and synapse responses, respectively. All of the current in HA-966 was blocked by D-aminophosphonovalerate (D-APV) $(50 \mu \mathrm{M}$; Fig. $6 \mathrm{~A})$, indicating that the faster decay was not produced by an incomplete block of non-NMDA receptors. To test whether this action of HA-966 required glycine, the experiment was repeated with no added glycine. In HA-966 alone, the EPSC and patch current amplitudes were decreased dramatically but the rates of decay were similar to those observed with added glycine (EPSC, $41.0 \pm 3.0$ msec, $n=5$; patch, $38.1 \pm 3.8 \mathrm{msec}, n=7$; data not shown).

We further examined the mode of action of HA-966 using outsidc-out patches. The extent of paired-pulse desensitization reflects the affinity of the NMDA receptor agonist (Lester and Jahr, 1992). In order to assess the effects of HA-966 on the unbinding rate of glutamate, we applied paired $10 \mathrm{msec}$ pulses of glutamate $(200 \mu \mathrm{M})$ in the presence and absence of HA-966. Consistent with an increased rate of glutamate unbinding, the extent of desensitization was dramatically decreased by HA-966 (Fig. $7 A$ ). At an interpulse interval of $320 \mathrm{msec}$, the second pulse had recovered to $76 \pm 5 \%$ in the presence of HA- 966 compared to only $45 \pm 7 \%$ in control glutamate $(n=3)$. The action of glutamate in the presence of HA-966 was very similar to the action of lower-affinity NMDA ligands, such as L-cysteate (Fig. $7 B$ ), providing supportive evidence that in the presence of HA966 the affinity of glutamate is decreased (Kemp and Priestley, 1991; Lester and Jahr, 1992). These data suggest that the binding of HA-966 to the glycine site of the NMDA receptor causes an increase in the unbinding rate of glutamate and results in a faster decay rate of the NMDA EPSC.

Because of the apparent allosteric modulation of glutamate affinity by HA-966, we tested two additional low-affinity glycine site agonists for their abilities to modulate the NMDA EPSC. The synaptic currents obtained in the presence of near saturating concentrations of glycine, L-serine, and L-alanine (McBain et al., 1989) are shown in Figure 8. In L-serine, EPSCs had the same amplitude (95\% of those in glycine; paired $t$ test, $p=0.17$; 


\section{A NMDA epsc}
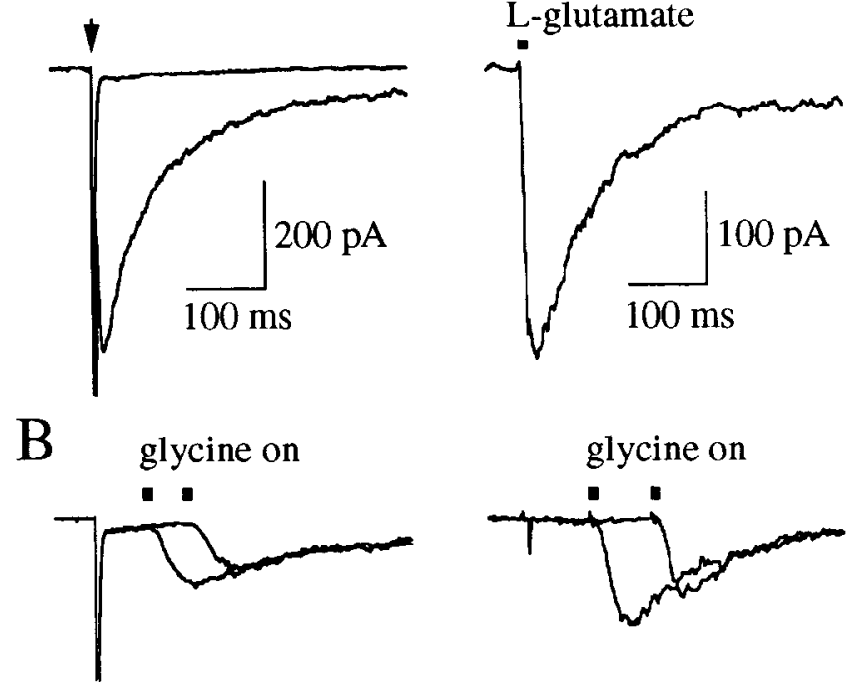

Figure 9. Glutamate remains bound to the NMDA receptor for prolonged periods in the absence of glycine. $A$, Averaged currents in response to autaptic stimulation (left) and a $10 \mathrm{msec}$ pulse of $200 \mu \mathrm{M}$ glutamate in an outside-out patch (right) in the continuous presence of glycine $(20 \mu \mathrm{M})$. The smaller current response in $A$ shows stimulation in the absence of added glycine and reveals the unclamped sodium spike in response to the stimulus. $B$, The same recordings as in $A$ except that glycine was absent during glutamate stimulation and added back at later times (squares). Note the absence of a response to glutamate application alone $(B$, right $)$.

$n=5)$ and decayed with a similar time course $(68.9 \pm 7.6 \mathrm{msec}$, fast decay time constant; $n=5$ ) compared to those obtained in glycine $(72.8 \pm 5.6 \mathrm{msec} ; n=16)$. For L-alanine, the EPSCs both were smaller (77\% of the EPSC in glycine; $p=0.02 ; n=$ 7) and decayed faster $(48.5 \pm 5.1 \mathrm{msec}, n=7)$. Thus, L-alanine behaved, albeit to a lesser extent, like HA-966.

The parallel action of HA-966 in both types of preparation supports the idea that NMDA receptors in excised patches and at synapses behave in a similar manner. A further manipulation was performed to test this proposal. The effects of delayed glycine introduction (relative to glutamate) were compared on EPSCs and patch currents. The synapse was stimulated in the absence of glycine and the presence of glycine site antagonist FIC, and then at times up to several hundred milliseconds later, glycine was introduced (without antagonist). This experiment resulted in an initial block of the NMDA EPSC that recovered at times corresponding to the addition of glycine (Fig. $9 A$ ). To determine if this was due to prolonged transmitter binding in the absence of glycine after free transmitter had been cleared from the synaptic cleft (see Hestrin et al., 1990; Lester et al., 1990), we repeated the experiment on the outside-out patch, substituting a $10 \mathrm{msec}$ pulse of glutamate $(200 \mu \mathrm{M})$ for transmitter. Figure $9 B$ shows that the patch currents, under these conditions, were comparable to the EPSC and indicates that glutamate remains bound to NMDA receptors for a prolonged period in the absence of glycine.

\section{Glutamate desensitizes NMDA receptors in the absence of glycine}

To obtain a more complete description of NMDA receptor activation, we have investigated the consequences of agonist bind-
A
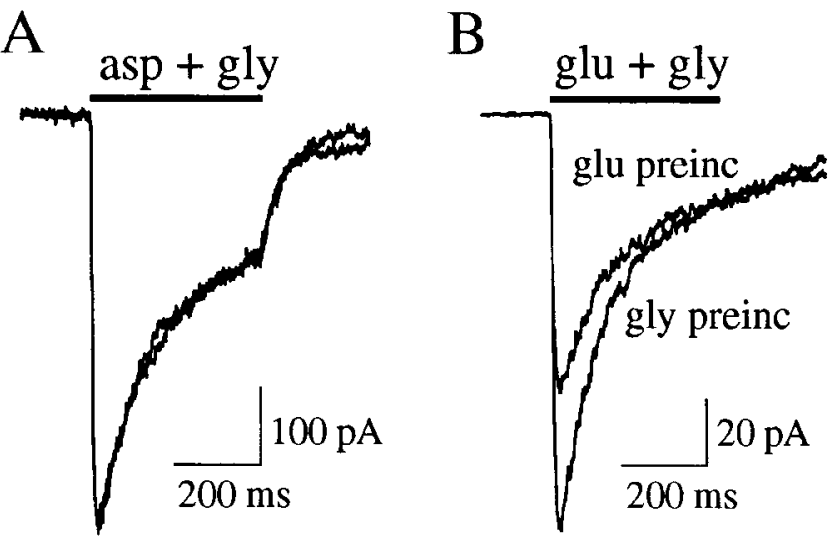

Figure 10. Glutamate alone desensitizes NMDA receptors. A, Averaged currents from an outside-out patch evoked by $400 \mathrm{msec}$ applications of $2 \mathrm{mM}$ L-aspartate and $10 \mu \mathrm{M}$ glycine with and without preincubation with $10 \mu \mathrm{M}$ glycine. Glycine was used at 10,20 , and $200 \mu \mathrm{M}$ in various experiments without any observed differences. $B$, Averaged currents from another patch activated by $400 \mathrm{msec}$ applications of glutamate $(200 \mu \mathrm{M})$ and glycine $(200 \mu \mathrm{M})$ with preincubation with $200 \mu \mathrm{M}$ glutamate or with preincubation with $20 \mu \mathrm{M}$ glycine. In $A, \mathrm{~L}$-aspartate was used instead of glutamate so that CNQX, which binds to the glycine site of the NMDA receptor (Lester et al., 1989), could be omitted from the solutions. This was necessary because the unbinding of CNQX will slow the rise time of the $\mathrm{L}$-aspartate/glycine response and artifactually reduce the amplitude. In $B$, the solutions used with the glutamate preincubation also did not contain CNQX for the same reason. However, CNQX was present at $2.5 \mu \mathrm{M}$ in the solutions used with glycine preincubation in order to block the AMPA receptor current at the onset of the glutamate pulse. Because CNQX has a lower affinity for the glycine site than glycine and was present at a much lower concentration than the preincubation concentration of glycine, an insignificant percentage of glycine sites would be bound by CNQX.

ing to each site in isolation. The effects of preincubation of outside-out patches in either glycine or glutamate before subsequent activation of NMDA receptors by both ligands were studied. Preincubation of patches with saturating concentrations of glycine (10-200 $\mu \mathrm{M})$ evoked no channel activity, and no reduction in the current amplitude in response to the addition of L-aspartate ( $2 \mathrm{mM})$ compared to the simultaneous application of both agonists (Fig. 10A). However, if the patch was preincubated with glutamate $(200 \mu \mathrm{M}$ for $10 \mathrm{sec})$, responses to the subsequent addition of glycine $(200 \mu \mathrm{M})$ were $32 \pm 2.7 \%$ smaller than those evoked by glutamate with glycine preincubation (Fig. $10 B$ ). These data are consistent with the suggestion that glutamate alone can drive the receptor into a desensitized state.

\section{Kinetics and glycine sensitivity of NMDA receptor desensitization are not constant between patches}

In the present study, we found two populations of "late" outsideout patches that differed in the time course of decay of NMDA receptor currents and the effects of glycine concentration (Fig. 11). The decay of NMDA receptor currents in response to 10 msec pulses of glutamate ( $200 \mu \mathrm{M}$, in $10 \mu \mathrm{M}$ glycine) in both populations were well fitted by two exponentials; the modal values of the first time constants were 80 and $120 \mathrm{msec}$, for "fast" and "slow" patches, respectively (Fig. 11 $A, C$ ). Although lowering the concentration of glycine reduced the peak response in both populations, the time course of responses in fast patches was insensitive to the concentration of glycine, whereas the first time constant of decay of the slow patch current was decreased to about $80 \mathrm{msec}$ in $100 \mathrm{~nm}$ glycine (Fig. $11 B, D$ ). These differ- 
A

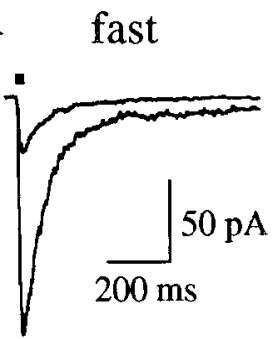

Figure 11. NMDA channels exist in more than one functional st ${ }^{-1}$ ' Fast and slow responses of $o$ :-out patches to $10 \mathrm{mscc}$ applicat $\mathrm{fglu}$ tamate $(200 \mu \mathrm{M})$ in the continuous presence of $10 \mu \mathrm{M}$ (large responses) and 100 nм (small responses) glycine. $B$, The same currents as in $A$ but normalized to their peak responses. $C$, Histogram of the time constant of the faster of two exponentials used to fit the responses evoked in saturating glycine concentrations (129 patches). $D$, Histogram of the mean fast time constants of "fast" $(n=10)$ and "slow" patches $(n=14)$ in the presence of $10 \mu \mathrm{M}$ and $100 \mathrm{nM}$ glycine. There was no correlation between the time constant and the response amplitude.

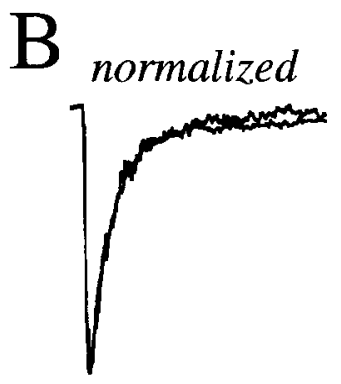

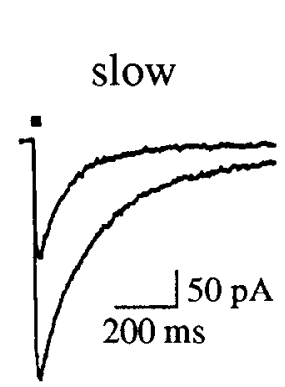

C
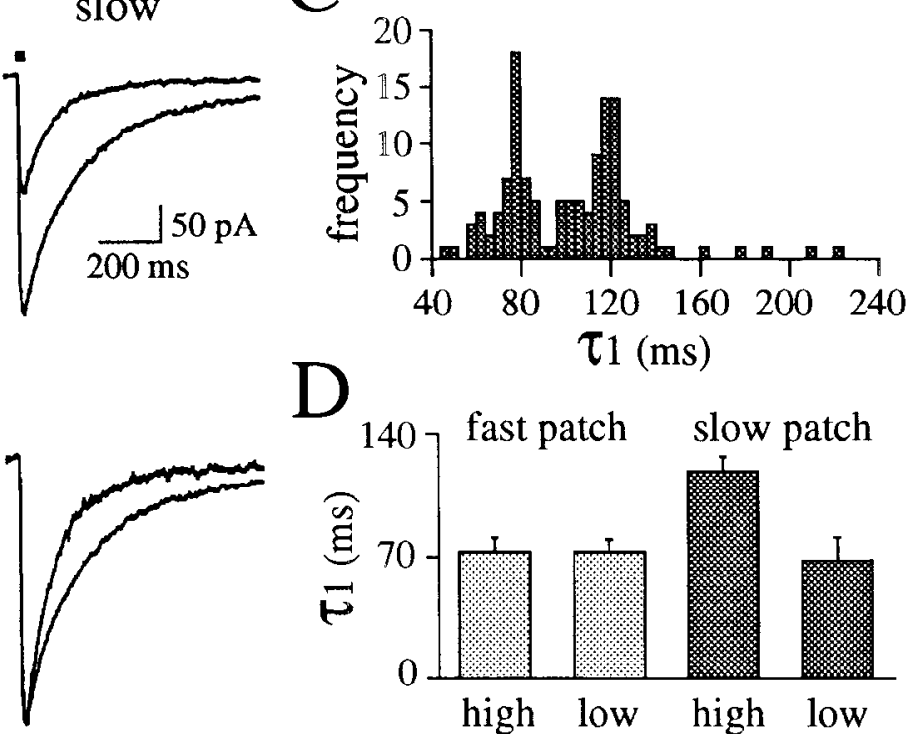

$\mathrm{D}$

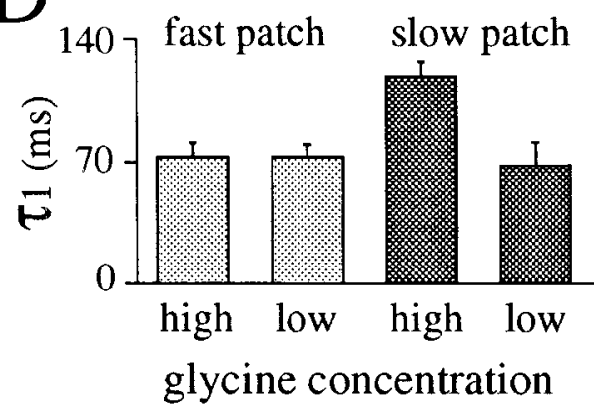

ences in decay time courses were not correlated with the response amplitude. In the present study, we did not observe the "slow" type of NMDA receptor behavior at synapses. Therefore, in order to avoid problems of interpretation, all preceding experiments were performed exclusively with "fast" patches that exhibited minimal glycine sensitive desensitization within 1-3 min after patch formation.

\section{Discussion}

Allosteric interactions at synaptic receptors provide a possible route through which modulation of neurotransmission may occur. Interactions between the glutamate and glycine binding sites of the NMDA receptor have been reported (Benveniste et al., 1990). The evidence presented in the present study indicates that such regulation may also occur at glutamatergic synapses.

\section{Activation of NMDA receptors by glutamate and glycine alone}

As a preliminary control for the major aims of the project, we have reinvestigated the conclusion that both glycine and glutamate are required for NMDA channel opening (see Kleckner and Dingledine, 1988). The data obtained in this study, on outside-out patches (with which there is very good control over the external composition of the media), also indicates that neither glutamate nor glycine alone can activate NMDA receptors. However, preincubation with glutamate decreased the response to subsequent applications of supersaturating concentrations of glycine without causing channel activity by itself. Although we have taken precautions to reduce glycine contamination to a minimum, we cannot absolutely rule out that remaining glycine contamination acted with glutamate to cause predesensitization of NMDA receptors. However, due to the extremely low level of residual glycine, we suggest that NMDA receptors may be desensitized by glutamate alone (see also Chizhmakov et al., 1992). In view of this result, the model described in the Results could be modified to include another desensitized state to which only glutamate is bound. The physiological consequences of glutamate-induced desensitization are unclear, as glycine is presumably always present in the synapse.

\section{Glycine-sensitive and-insensitive desensitization modulate NMDA currents in outside-out patches}

Although NMDA receptor desensitization is sensitive to the concentration of glycine in undialyzed hippocampal neurons (Mayer et al., 1989; Benveniste et al., 1990; Vyklicky et al., 1990), it is apparently insensitive in outside-out patches (Sather et al., 1990) and acutely isolated cells (Shirasaki et al., 1990; Chizhmakov et al., 1992). These two apparently opposite results can be integrated in a single model if additional factors are taken into consideration. Regulation of NMDA receptors is complex and probably involves cytoplasmic components (MacDonald et al., 1989). Loss of these components may contribute to timedependent increases in the rate of glycine-insensitive desensitization as recently reported (Chizhmakov et al., 1992; Lester and Jahr, 1992; Sather et al., 1992). It appears that these changes occur fastest in outside-out patches (Lester and Jahr, 1992), more slowly in acutely isolated cells (Chizhmakov et al., 1992) and "nucleated" patches (Sather et al., 1992), and slowest in large whole-cell recordings (Benveniste et al., 1990). Why such changes occur is not known, but since in undialyzed cells (Mayer and Westbrook, 1985; Zorumski et al., 1989; Benveniste et al., 1990), but not patches (Sather ct al., 1990), desensitization is also dependent on the concentration of $\mathrm{Ca}^{2+}$, one may speculate that a cytoplasmic $\mathrm{Ca}^{2+}$-binding protein is involved.

To understand the complex and time-dependent effects observed in outside-out patches, it is important to compare the behavior of NMDA receptors before and after internal dialysis. Because the effects of glycine concentration on NMDA receptor currents in "early" palches are very similar to that observed in whole-cell recordings (Mayer et al., 1989), there is no reason not to assume a similar underlying mechanism, that is, that glutamate changes the affinity for glycine (Benveniste et al., 1990 ), and this results in glycine-sensitive desensitization. With time, the increase in the rate of glycine-insensitive desensitization occludes glycine concentration-dependent effects. As indicated by the dependence of the glycine unbinding rate on the presence or absence of glutamate, the negative allosteric inter- 
action between the glutamate and glycine sites still exists in "late" patches. We suggest, therefore, that the allosteric interaction probably occurs at the level of the receptor channel protein and does not require cytoplasmic factors. The potential for such a nonlabile allosteric interaction is supported by the recent evidence that both glutamate and glycine can bind to the same protein (Moriyoshi et al., 1991). The overall pattern of desensitization that is observed will therefore be a composite of the two forms.

These conclusions are fully consistent with the model described in the present article. Others have used a cyclic scheme (Katz and Thesleff, 1957) to describe the behavior of NMDA receptors (Sather et al., 1992). It was our primary intention here to account for the interaction of the glycine-dependent and -independent forms of desensitization, and it is likely that a more detailed scheme will be required to completely describe the kinetic behavior of NMDA receptors. However, even the simple model that we and Benveniste et al. (1990) have proposed accounts reasonably well for the apparent affinities of peak, steady state, and predesensitization as measured by Sather et al. (1992).

\section{Allosteric interactions at synaptic NMDA receptors}

Although considerable information regarding the detailed kinetic behavior of NMDA channels exists, little work has been performed at excitatory synapses. As NMDA receptors are involved in the regulation of synaptic efficacy (Collingridge and Singer, 1990), and pharmacological blockade of the glycine site prevents long-term potentiation (Bashir et al., 1990), it is important to understand the regulatory role of glycine at these sites. Ilowever, until Kemp and Priestley (1991) observed that HA-966 increased the dissociation rate of glutamate from the NMDA receptor, there were no direct means to test whether substances acting at the glycine site could allosterically modulate binding at the glutamate binding site. The finding that HA-966 increased rate of decay of the NMDA EPSC argues that modulation does occur. Indeed, the NMDA EPSC behaved as if it was mediated by a transmitter with an affinity between that of L-aspartate and L-cysteate, 10-100-fold lower than that of glutamate, as assessed by a more careful characterization of the action of HA-966 on outside-out patches. As NMDA receptors in patches are kinetically similar to those activated synaptically (Lester et al., 1990; Lester and Jahr, 1992), we suggest that the allosteric interactions between glutamate and glycine binding sites, reported here for patch receptors, can be extended to include NMDA receptors at excitatory synapses. These results corroborate those of other studies that conclude that NMDA receptors in patches and at synapses are very similar (Lester et al., 1990; Robinson et al., 1991; Lester and Jahr, 1992).

We have suggested that the slow second component of the decay of synaptic NMDA currents is due to continual reopening of channels from a bound desensitized state that results from the very slow unbinding of a high-affinity transmitter like glutamate (Lester and Jahr, 1992). If the affinity of the transmitter is reduced, such as in the presence of HA-966, we would predict not only an increase in the faster first component of the EPSC decay but also a reduction in the slower second component. That this is observed provides the further support for the involvement of desensitization in controlling the time course of the NMDA EPSC (Lester and Jahr, 1992). One caveat to our experiments is that $300 \mathrm{~nm}$ glycine was present during most of the HA-966 applications. In those cases in which glycine was omitted, the synaptic and patch currents became very small in amplitude but the rate of relaxation, although difficult to measure accurately, was increased to a similar extent. A possible interpretation of these effects is that occupation of one of the two glycine sites on the NMDA receptor by HA-966 results in a decreased affinity of at least one glutamate binding site. Because both glutamate sites must be bound for significant channel opening to occur, the decreased affinity of one glutamate site should be sufficient for an increased rate of decay of the current.

Synaptic stimulation or glutamate application to patches results in little or no NMDA channel activation when measures are taken to reduce glycine contamination. Subsequent addition of glycine, even hundreds of milliseconds later, however, results in currents that are similar in amplitude to those that would still be active had glycinc becn continuously present. These findings indicate that glutamate in the absence of glycine remains bound to NMDA receptors for prolonged periods and, furthermore, at least a subset of the glutamate-bound receptors remain in an activatable state.

\section{Conclusions}

The evidence presented in this article accounts for both the glycine-sensitive and -insensitive desensitization and the potentiating effect of glycine and suggests that all these effects contribute to the overall behavior of NMDA channels. Whether all NMDA receptors are modulated by glycine is as yet unclear. Differences in glycine sensitivity have been reported in NMDA receptor binding studies (Monaghan et al., 1988) and in NMDA channels expressed in oocytes using cerebellar mRNA (Sekiguchi et al., 1990). The present data suggest that NMDA channels from hippocampal neurons may not all be in the same state and that this may affect their modulation by glycine. The observed "fast" and "slow" types of NMDA channel behavior may be a result of differences in the dissociation rate of glutamate known to occur in subtypes of cloned NMDA receptors (Monyer et al., 1992). For a more complete description of NMDA channel function and plasticity, it will be necessary to resolve the mechanisms responsible for the changes that occur during internal dialysis.

\section{References}

Bashir ZI, Tam B, Collingridgc GL (1990) Activation of the glycine site in the NMDA receptor is necessary for the induction of LTP. Neurosci Lett 108:261-266.

Bekkers JM, Stevens CF (1991) Excitatory and Inhibitory autaptic currents in isolated hippocampal neurons maintained in cell culture. Proc Natl Acad Sci USA 88:7834-7838.

Benveniste M, Mayer ML (1991) Kinetic analysis of antagonist action at $N$-methyl-D-aspartate receptors: two binding sites each for glutamate and glycine. Biophys J 59:560-573.

Benveniste M, Vyklicky L Jr, Mayer ML, Clements J (1990) A kinetic analysis of the modulation of $N$-methyl-D-aspartic acid receptors by glycine in mouse cultured hippocampal neurones. J Physiol (Lond) 428:333-357.

Chizhmakov IV, Kiskin NI, Krishtal OA (1992) Two types of steadystate desensitization of $N$-methyl-D-aspartate receptors in isolated hippocampal neurons of rat. J Physiol (Lond) 448:453-472.

Clements JD, Westbrook GL (1991) Activation kinetics reveal the number of glutamate and glycine binding sites on the $N$-methyl-Daspartate receptor. Neuron 7:605-613.

Collingridge GL, Singer W (1990) Excitatory amino acid receptors and synaptic plasticity. Trends Pharmacol Sci 11:290-296.

Fletcher EJ, Lodge D (1988) Glycine reverses antagonism of $N$-methylD-aspartate (NMDA) by 1-hydroxy-3-aminopyrrolidone-2-one (HA966) but not by D-2-amino-5-phosphonovalerate (D-AP5) on rat cortical slices. Eur J Pharmacol 151:161-162. 
Forsythe ID, Westbrook GL, Mayer ML (1988) Modulation of excitatory synaptic transmission by glycine and zinc in cultures of mouse hippocampal neurons. J Neurosci 8:3733-3741.

Henderson G, Johnson JW, Ascher P (1990) Competitive antagonists and partial agonists at the glycine modulatory site of the mouse $\mathrm{N}$-methyl-D-aspartate receptor. J Physiol (Lond) 430:189-212.

Hestrin S, Sah P, Nicoll RA (1990) Mechanisms gencrating the time course of dual component excitatory synaptic currents recorded in hippocampal slices. Neuron 5:247-253.

Huettner JE (1991) Competitive antagonism of glycine at the $N$-methyl-D aspartate (NMDA) receptor. Biochem Pharmacol 41:9-16.

Jahr CE (1992) High probability opening of NMDA receptor channels by L-glutamate. Science $255: 470-472$.

Johnson JW, Ascher P (1987) Glycine potentiates the NMDA response in cultured mouse brain neurons. Nature 325:529-531.

Johnson JW, Ascher P (1992) Equilibrium and kinetic study of glycine action on the $N$-methyl-D-aspartate receptor in cultured mouse brain neurons. J Physiol (Lond) 455:339-365.

Katz B, Thesleff S (1957) A study of the desensitization produced by acetylcholine at the motor end-plate. J Physiol (Lond) 138:63-80.

Kcmp JA, Pricstlcy T (1991) Effects of (+)-HA-966 and 7-chlorokynurenic acid on the kinetics of $N$-methyl-D-aspartate receptor agonist responses in rat cultured cortical neurons. Mol Pharmacol 3: 666-670.

Kleckner NW, Dingledine R (1988) Requirement for glycine in activation of NMDA-receptors expressed in Xenopus oocytes. Science 241:835-837.

Lester RAJ, Jahr CE (1992) NMDA channel behavior depends on agonist affinity. J Neurosci 12:635-643.

Lester RAJ, Quarum ML, Parker JD, Weber E, Jahr CE (1989) Interaction of 6-cyano-7-nitroquinoxaline-2,3-dione with the $N$-methyl-D-aspartate receptor-associated glycine site. Mol Pharmacol 35: 565-570.

Lester RAJ, Clements JD, Westbrook GL, Jahr CE (1990) Channel kinetics determine the time course of NMDA receptor-mediated synaptic currents. Nature 346:565-567.

MacDonald JF, Mody I, Salter MW (1989) Regulation of $N$-methylD-aspartate receptors revealed by intracellular dialysis of murine neurones in culture. J Physiol (Lond) 414:589-596.

Mayer ML, Westbrook GL (1985) The action of $N$-methyl-D-aspartic acid on mouse spinal neurones in culture. J Physiol (Lond) 361:6590.

Mayer ML, Vyklicky L Jr, Clements J (1989) Regulation of NMDA receptor desensitization in mouse hippocampal neurons by glycine. Nature 338:425-427.
McBain CJ, Kleckner NW Wyrick S, Dingledine R (1989) Structural requirements for activation of the glycine coagonist site of $N$-methylD-aspartate receptors expressed in Xenopus oocytes. Mol Pharmacol 36:556-565.

Monaghan DT, Olverman HJ, Nguyen L, Watkins JC, Cotman CW (1988) Two classes of $N$-methyl-D-aspartate recognition sites: diffcrential distribution and differential regulation by glycine. Proc Natl Acad Sci USA 85:9836-9840.

Monyer H, Sprengel R, Schoepfer R, Herb A, Higuchi M, Lomeli H, Burnashev N, Sakmann B, Seeberg PH (1992) Heteromeric NMDA receptors: molecular and functional distinction of subtypes. Science 266:1217-1221.

Moriyoshi K, Masu M, Takahiro I, Shigemoto R, Mizuno N, Nakanishi $S$ (1991) Molecular cloning and characterization of the rat NMDA receptor. Nature 354:31-37.

Robinson HPC, Sahara Y, Kawai N (1991) Nonstationary fluctuation analysis and direct resolution of single channel currents at postsynaptic sites. Biophys J 59:295-304.

Sather W, Johnson JW, Henderson G, Ascher P (1990) Glycine-insensitive desensitization of NMDA responses in cultured mouse embryonic ncurons. Ncuron 4:725-731.

Sather W, Dieudonne S, MacDonald JF, Ascher P (1992) Activation and desensitization of $N$-methyl-D-aspartate receptors in nucleated patches from mouse neurones. J Physiol (Lond) 450:643-672.

Sekiguchi M, Okamoto K, Sakai Y (1990) Glycine-insensitive NMDAsensitive receptor expressed in Xenopus oocytes by guinea pig cerebellar mRNA. J Neurosci 10:2148-2155.

Shirasaki T, Nakagawa T, Wakamori M, Tateishi N, Fukuda A, Murase $\mathrm{K}$, Akaike N (1990) Glycine-insensitive desensitization of $N$-methyl-D-aspartate receptors in acutely isolated mammalian central neurons. Neurosci Lett 108:93-98.

Thomson AM (1991) Glycine modulation of the NMDA receptor/ channel complex. Trends Pharmacol Sci 12:349-353.

Thomson AM, Walker VE, Flynn DM (1989) Glycine enhances NMDA-receptor mediated synaptic potentials in neocortical slices. Nature 338:422-424.

Vyklicky L Jr, Benveniste M, Mayer ML (1990) Modulation of $N$-methyl-D-aspartic acid receptor desensitization by glycine in mouse cultured hippocampal neurones. J Physiol (Lond) 428:313-331.

Zorumski CF, Yang J, Fischbach GD (1989) Calcium-dependent, slow desensitization distinguishes different types of glutamate receptors. Cell Mol Neurobiol 9:95-104. 